\title{
D-region electron density and effective recombination coefficients during twilight - experimental data and modelling during solar proton events
}

\author{
A. Osepian ${ }^{1}$, S. Kirkwood ${ }^{2}$, P. Dalin ${ }^{2}$, and V. Tereschenko ${ }^{1}$ \\ ${ }^{1}$ Polar Geophysical Institute, Chalturuna 15, 183010 Murmansk, Russia \\ ${ }^{2}$ Swedish Institute of Space Physics, P.O. Box 812, 98128 Kiruna, Sweden
}

Received: 11 June 2009 - Revised: 28 August 2009 - Accepted: 18 September 2009 - Published: 2 October 2009

\begin{abstract}
Accurate measurements of electron density in the lower D-region (below $70 \mathrm{~km}$ altitude) are rarely made. This applies both with regard to measurements by ground-based facilities and by sounding rockets, and during both quiet conditions and conditions of energetic electron precipitation. Deep penetration into the atmosphere of high-energy solar proton fluxes (during solar proton events, SPE) produces extra ionisation in the whole D-region, including the lower altitudes, which gives favourable conditions for accurate measurements using ground-based facilities. In this study we show that electron densities measured with two ground-based facilities at almost the same latitude but slightly different longitudes, provide a valuable tool for validation of model computations. The two techniques used are incoherent scatter of radio waves (by the EISCAT $224 \mathrm{MHz}$ radar in Troms $\varnothing$, Norway, $69.6^{\circ} \mathrm{N}, 19.3^{\circ} \mathrm{E}$ ), and partial reflection of radio-waves (by the $2.8 \mathrm{MHz}$ radar near Murmansk, Russia, $69.0^{\circ} \mathrm{N}$, $35.7^{\circ} \mathrm{E}$ ). Both radars give accurate electron density values during SPE, from heights $57-60 \mathrm{~km}$ and upward with the EISCAT radar and between 55-70 km with the partial reflection technique. Near noon, there is little difference in the solar zenith angle between the two locations and both methods give approximately the same values of electron density at the overlapping heights. During twilight, when the difference in solar zenith angles increases, electron density values diverge. When both radars are in night conditions (solar zenith angle $>99^{\circ}$ ) electron densities at the overlapping altitudes again become equal. We use the joint measurements to validate model computations of the ionospheric parameters $f^{+}, \lambda, \alpha_{\text {eff }}$ and their variations during solar proton events. These parameters are important characteristics of the lower ionosphere structure which cannot be determined by other methods.
\end{abstract}

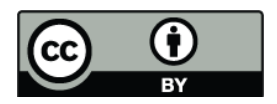

Correspondence to: S. Kirkwood (sheila.kirkwood@irf.se)
Keywords. Ionosphere (Auroral ionosphere; Ion chemistry and composition; Plasma temperature and density)

\section{Introduction}

The high-latitude ionosphere has been intensively studied using various ground-based facilities as well as rocket and satellite-borne instruments. There are a number of reasons to study the polar ionosphere. From a scientific point of view, the high latitude ionosphere is the region most affected by magnetosphere-ionosphere interactions, responding strongly to the extremely complex Sun-magnetosphereionosphere chain of physical processes. The interaction of solar wind plasma with the terrestrial atmosphere causes many, very complicated, physical, chemical and dynamical phenomena in the lower polar ionosphere and mesosphere. As a result of the extremely variable ionising input in the form of energetic charged particles, the strong dependencies of ion chemistry on season and solar zenith angle, and the strong sensitivity to dynamics, the structure of the lower ionosphere is highly variable. Important features of the lower ionosphere include the existence of many types of cluster ions and various negative ions, redistribution of their abundance and of electron concentration during particle precipitation, as well as a significant role for minor neutral constituents in the processes determining the ionisation balance.

The strong and irregular spatial and temporal variations in the ionised components and in dynamical processes have a significant influence on the formation of in-homogeneous structures. These affect operation of various ground-based and satellite-borne radio engineering facilities, which are used for radio communication over a broad frequency range. In disturbed conditions, the D-region of the ionosphere (50$90 \mathrm{~km}$ ) impacts substantially on radio wave propagation, through the absorption of wave energy. The operation of navigation and communication systems in the VLF/LF range

Published by Copernicus Publications on behalf of the European Geosciences Union. 
depends on the stability of the lower border of the D-region, where these waves are reflected. The use of HF-radiowaves for long-distance broadcasting depends on the absorption in the lower ionosphere. The increase of electron density in the polar ionosphere during high energy electron precipitation (auroral absorption events) and solar proton precipitation (solar proton events, SPE) leads to enhancement of HF radio wave absorption. This can cause long-lasting blackouts on the polar radio paths and can change the amplitude and phase of VLF-radio waves. So investigation of the lower ionosphere and examination of its structure is still important for both scientific and practical reasons.

To improve propagation prediction methods and to ensure the practicability of radio communication requires knowledge of the spatial and temporal distribution of the electron density profiles in various conditions (quiet and disturbed situations, different seasons and solar zenith angles). Empirical and semi-empirical models describing the height distribution of electron density (Friedrich and Torkar, 1992, 1995, 1998a,b, 2001; Friedrich and Kirkwood, 2000; Friedrich et al., 2006; McKinnell and Friedrich, 2007) are available, based mainly on measurements of the electron concentration using radio-wave propagation methods and sounding rockets. However, despite a very large number of experimental investigations, there are problems in predicting ionospheric parameters with sufficient accuracy in many geophysical situations. Moreover experimental data on the lower part of the D-region are often absent, usually because the very low values of electron density at altitudes below $70 \mathrm{~km}$ are very difficult to measure, especially during quiet conditions, but even during auroral events when the energies of precipitating electrons are generally too low to cause ionisation at Dregion heights. As a result, even the most comprehensive empirical model, the International Reference Ionosphere model (IRI, see Bilitza and Reinisch, 2008, and references therein) is not intended to be applied to the auroral zone, and as such does not meet all of the necessary requirements either for scientific applications or for forecasting radio wave propagation over a wide range of frequencies.

Theoretical investigations allow us to understand the nature of, and the reasons for, the variability of ionospheric parameters and to produce models which take into account all the factors which influence the structure of the ionosphere and the electron density in the corresponding geophysical conditions. Thus theoretical models can provide us with information on ionospheric parameters that are important for describing and understanding the structure of the lower ionosphere structure, even if these quantities cannot be estimated from standard measurements. For example, for any geophysical situation, theoretical models allow us to determine the height distribution of different positive and negative ions and of electron density, including the lower part of the D-region, and to find the height, $h_{f^{+}=1}$, at which the transition from simple molecular ions to complex ion clusters takes place, and the height, $h_{\lambda=1}$, where the concentration of the nega- tive ions begins to dominate over the electron concentration. Theoretical models allow us to estimate height profiles of effective recombination coefficient which can in principle not be measured. With the help of theoretical models we can study changes of ionospheric parameters due to both different external phenomena (magnetospheric, solar or artificial) and to other possible sources (e.g. minor constituent concentrations) and to separate the different effects.

In this study we use electron concentrations measured in the D-region by two different ground-based methods: incoherent scatter of radio waves using the EISCAT $224 \mathrm{MHz}$ radar, near Troms $\varnothing$, Norway, at $69.6^{\circ} \mathrm{N}, 19.3^{\circ} \mathrm{E}$, and the partial reflection technique, using the $2.8 \mathrm{MHz}$ radar, near Murmansk in Russia, at $69.0^{\circ} \mathrm{N}, 35.7^{\circ} \mathrm{E}$. We use observations by the two radars at the same universal times, but at different solar zenith angles $(\chi)$, and compare the observations with each other and with the results of model calculations. We use 1min time-averages from both radars, with height resolution $1 \mathrm{~km}$ for EISCAT and $1.5 \mathrm{~km}$ for the partial reflection radar. We use experimental data from both radars during the solar proton event on 17 January 2005, when the ionisation rate in the D-region is large and measurements of electron density in the lower ionosphere $(h<70 \mathrm{~km})$ are more accurate than for other conditions. We also use experimental data on electron density obtained with the EISCAT radar at the time of the very strong SPE on 29-30 October 2003. Under conditions of strong and long duration disturbances (such as SPE), there is both a large increase in ionisation and changes in the neutral composition. On the basis of model computations we investigate variations of ion composition, electron density and effective coefficient recombination at different altitudes in the D-region produced by the solar proton fluxes. The model allows us to separate effects due directly to the growth of ion production rate from those due to changes in the concentration of minor neutral species $\left(\mathrm{NO}, \mathrm{O}, \mathrm{O}_{3}\right)$ caused by the solar proton precipitation. Comparison of the calculated and measured electron density profiles gives the possibility to estimate the contribution both of the direct ionisation process and of minor neutral species to changing the ionospheric parameters. It also allows us to determine profiles of effective recombination coefficient as a function of $\chi$.

\section{Model calculations}

Owing to the relatively short lifetime of the ions in the lower ionosphere, a steady-state computation of the plasma densities provides an adequate description over a wide range of conditions and electron density $N_{e}$ can be considered to be the result of an equilibrium between ion production rate, $q$, and effective electron loss

$q=\alpha_{\mathrm{eff}} N_{e}^{2}$ 
Here $\alpha_{\text {eff }}$ denotes the "effective recombination coefficient", which is determined by the expression:

$\alpha_{\mathrm{eff}}=(1+\lambda)\left(\alpha_{d}+\lambda \alpha_{i}\right)$

$\alpha_{d}=\frac{\alpha_{\mathrm{NO}^{+}, \mathrm{O}_{2}^{+}}+f^{+} \alpha_{\mathrm{Cl}^{+}}}{1+f^{+}}, \quad f^{+}=\frac{\left[\mathrm{CL}^{+}\right]}{\left[\mathrm{NO}^{+}\right]+\left[\mathrm{O}_{2}^{+}\right]}$

where $\alpha_{i}$ is the coefficient of ion-ion recombination between positive and negative ions, $\alpha_{\mathrm{NO}^{+}, \mathrm{O}^{+}}$and $\alpha_{\mathrm{Cl}^{+}}$are average dissociative recombination coefficients of simple molecular ions and of cluster ions, respectively (Danilov, 1981; Danilov and Smirnova, 1993). The average recombination coefficient $\alpha_{d}$ depends on $f^{+}$, the ratio of positive cluster ions to simple molecular ions. At altitudes below about $70-75 \mathrm{~km}$ the value of $\alpha_{\text {eff }}$ depends on the ratio of total negative ions to electrons $\left(\lambda=N^{-} / N_{e}\right)$. It is clear that if a theoretical model describes the principal features of ion composition behaviour in various conditions, in good agreement with experimental data, it also describes the effective recombination coefficient and the electron density. Therefore, the principal purpose, and at the same time the complexity, of the ion-chemical model construction, is the correct description of cluster-ion formation from the simple ions, as well as description of the processes of negative-ion formation and loss in various conditions. In our study we apply the theoretical ionisation-recombination model of the D-region developed by Smirnova et al. (1988) and Osepian and Smirnova (1997), modified for SPE as described in Kirkwood and Osepian (1995) and Osepian et al. (2008, 2009). The model consists of several blocks: ionchemical model; calculation of ion pair production rates with all sources of ionisation (electromagnetic solar radiation, Ly$\alpha$ and Ly- $\beta$ scatter emissions, solar X-rays, galactic cosmic rays and high energy particles); neutral atmosphere model, including minor species; calculation of the effective electronneutral collision frequency and radio wave absorption.

In our ion-chemical model, complex transformations and formations of different ions which are usually described by large numbers of ion-chemical reactions in detailed schemes (Arnold and Krankowsky, 1971; Arnold, 1980; Ferguson, 1976; Reid, 1977; Chakrabarty et al., 1978; Turunen and Ranta, 1992; Kull et al., 1997; Kazil et al., 2003) are substituted by effective rate coefficients. The latter include the rates of the main ionic transformation processes and contain the dependencies on the neutral temperature and density, humidity and the concentration of the minor neutral species. The main ion-chemical reactions and efficiencies of ion-molecular reactions, in particular with minor neutral species, forming complex negative ions and positive clusters in the lower ionosphere, are described in earlier papers (Osepian et al., 2008, 2009). The model calculates the height distribution of the main positive ions $\left(\mathrm{O}_{2}^{+}, \mathrm{NO}^{+}\right.$, hydrated clusters combined into a cluster ${ }_{1}^{+}$family with recombination coefficient $\alpha \sim 2 \times 10^{-6} \mathrm{~cm}^{3} \mathrm{~s}^{-1}$, and proton hydrates combined into a cluster ${ }_{2}^{+}$family with $\alpha \sim 1 \times 10^{-5} \mathrm{~cm}^{3} \mathrm{~s}^{-1}$ ), main

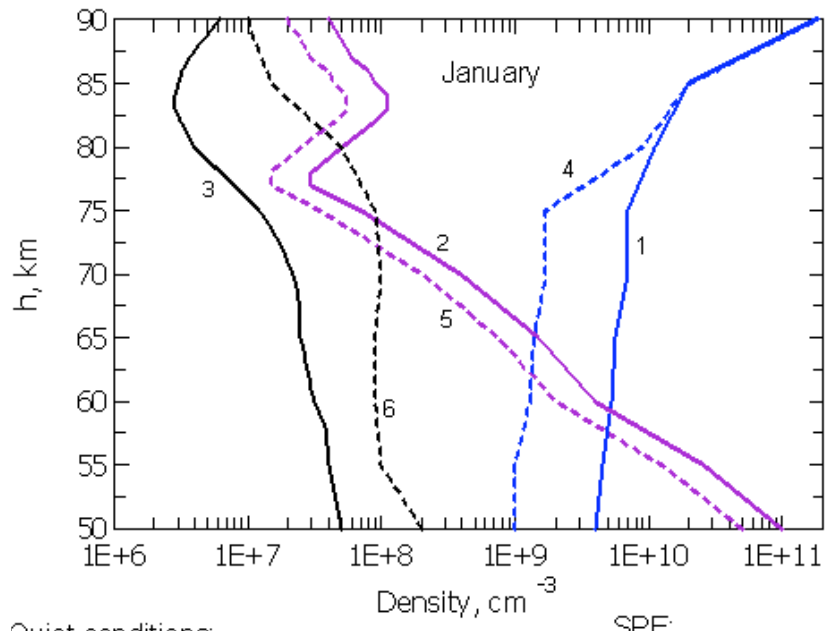

Quiet conditions:

SPE:

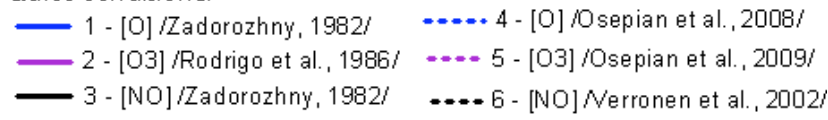

Fig. 1a. Winter: Input values of atomic oxygen (curves 1 and 4), ozone (curves 2 and 5) and nitric oxide (curves 3 and 6) concentrations. Curves 1-3 - during quiet conditions; curves 4-6 - during SPE. All profiles for $\chi<90^{\circ}$.

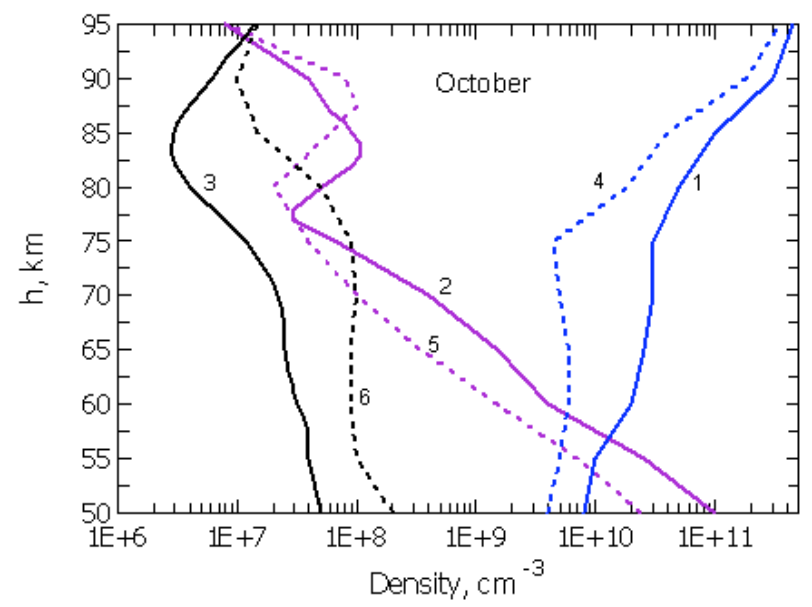

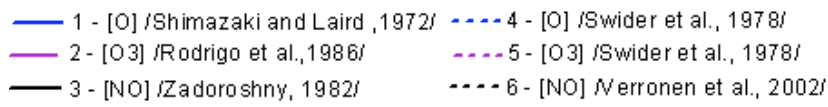

Fig. 1b. Autumn: Input values of atomic oxygen (curves 1 and 4), ozone (curves 2 and 5) and nitric oxide (curves 3 and 6) concentrations. Curves 1-3 - during quiet conditions; curves 4-6 - during SPE. All profiles for $\chi<90^{\circ}$.

negative ions, $\mathrm{O}_{2}^{-}, \mathrm{O}^{-}, \mathrm{CO}_{3}^{-}, \mathrm{NO}_{3}^{-}$, effective recombination coefficient and electron density. 


\subsection{Minor neutral constituents}

We present results of the modelling for SPE on 17 January 2005 and 29 October 2003. It is known that the concentrations of a number of minor neutral constituents, which are input parameters into the model, can change significantly during SPE. Figure 1 shows input values for atomic oxygen, ozone and nitric oxide at local noon under quiet conditions (curves 1-3) and during solar proton precipitation (curves 46). For the winter mesosphere (upper panel) the $\mathrm{O}$ and $\mathrm{NO}$ profiles in quiet conditions (curves 1 and 3) are taken from the diffusion photochemical model by Zadorozhny (1982). The $\mathrm{O}_{3}$-profile (curve 2 ) is taken from the diffusion photochemical model by Rodrigo et al. (1986). For autumn (lower panel) the concentration of $\mathrm{O}$ is from the diffusion photochemical model by Shimazaki and Laird (1970, 1972), $\mathrm{O}_{3}-$ from the model by Rodrigo et al. (1986), NO from the model by Zadorozhny (1982). It should be mentioned that the theoretical model with these input values of minor species, 1-3, has been tested for quiet conditions and for auroral events and has shown good results at altitudes at or above $70 \mathrm{~km}$, in both the night and morning local-time sectors (Osepian and Kirkwood, 1996; Osepian et al., 1995, 2000, 2001; Kirkwood et al., 2001).

The effect of solar proton precipitation on the minor species consists in enhanced concentration of nitric oxide and depletion of atomic oxygen and ozone concentrations (see e.g. Swider and Keneshea, 1973; Jackman and McPeters, 2004). For the winter mesosphere, the $\mathrm{O}$ and $\mathrm{O}_{3}$-profiles (curves 4, 5) are taken from results by Osepian et al. (2008, 2009); for October they are taken from the neutral chemistry model for the SPE-disturbed D-region (Swider and Keneshea, 1973; Swider et al., 1978). During SPE, concentrations of $\mathrm{O}$ and $\mathrm{O}_{3}$ are less than in quiet conditions. The concentration of nitric oxide during SPE is substantially larger than in quiet conditions. The NO- profile (curve 6) has been deduced for SPE in the model by Verronen et al. (2002). The changes of the odd oxygen concentration with $\chi$ during twilight are calculated using the simulation results by Turco and Sechrist (1972). We have assumed diurnal variations of NO and $\mathrm{NO}_{2}$ concentrations at altitudes below $75 \mathrm{~km}$ following the results of Ogawa and Shimazaki (1975).

\subsection{Ion production rates}

Figure 2 shows differential solar proton fluxes in several energy intervals and the hard solar X-ray intensity measured by the satellite GOES-10 on 17 January 2005 (NGDC, access: 1 April 2008). The data have a time resolution of $5 \mathrm{~min}$. It is seen that the strong solar flare results in a sharp increase of the solar X-ray intensity, with maximum intensity (fluxes $j_{1}(0.5-3.0 \AA)=9.2 \times 10^{-5} \mathrm{watt} / \mathrm{m}^{2}$ and $j_{2}$ $(1.0-8.0 \AA)=4.1 \times 10^{-4}$ watt $\left./ \mathrm{m}^{2}\right)$ at 09:50 UT. A change in the hardness of the energy spectrum of the proton flux can also be seen, with with the fluxes at the highest energies in-
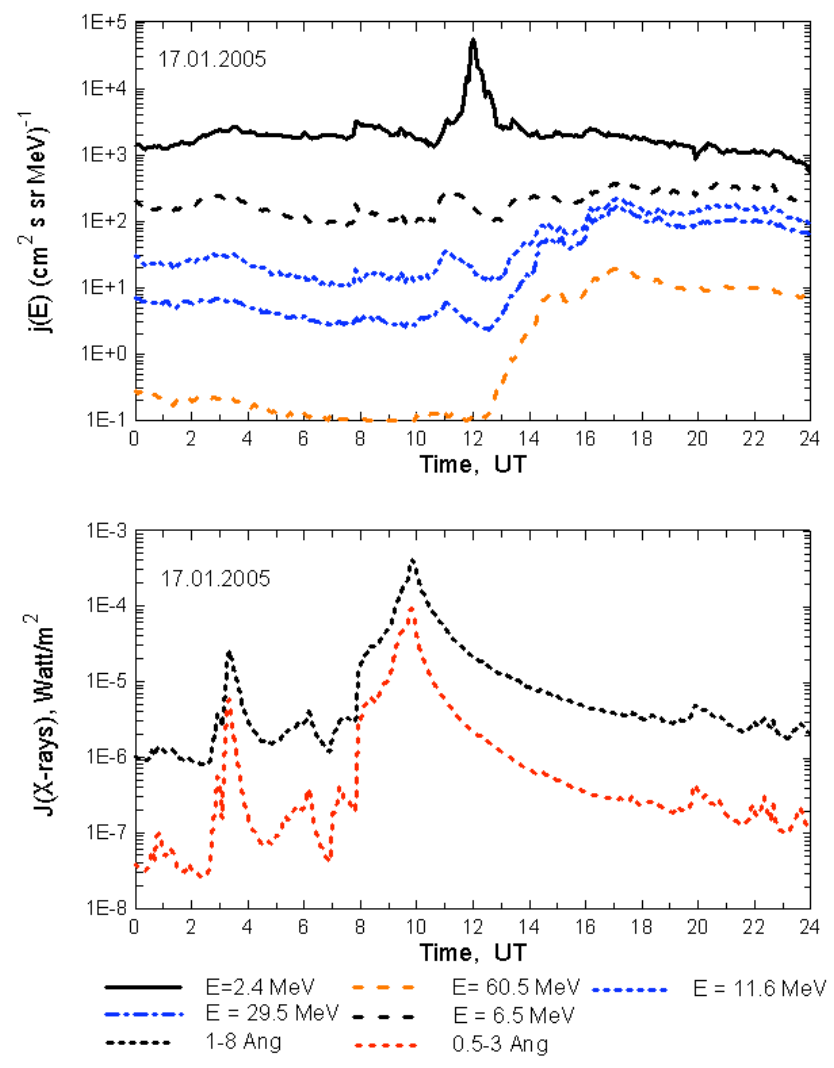

Fig. 2 . Differential solar proton fluxes and hard solar X-rays intensity observed on 17 January 2005.

creasing after 13:00 UT. Differential solar proton fluxes and hard solar X-ray intensity on 29 October 2003 are presented in Fig. 3.

Figure 4 shows ion pair production rate profiles in the lower ionosphere produced by solar proton fluxes in the energy range $2.4-100 \mathrm{MeV}$ (curve 1), solar X-rays (curve 2) and in quiet conditions (curve 3 - no particle precipitation or X-ray flash) calculated for 09:50 UT on 17 January 2005. It is clear that at latitudes $69.0^{\circ}$ and $69.6^{\circ}$, and at solar zenith angle $\chi \approx 90^{\circ}$ the ionisation rates from the hard solar $\mathrm{X}$-rays are significantly less (by about an order of magnitude) than those due to proton fluxes. Curves 4 and 5 present ion pair production rates for solar proton fluxes at 10:00 UT $\left(\chi \approx 84.7^{\circ}\right)$ on 29 October 2003 and 09:00 UT $\left(\chi \approx 86.7^{\circ}\right)$ on 30 October 2003 (note that the measurements are made in polar winter so that the Sun is only a few degrees above the horizon even at mid-day). Ion pair production rates for the solar proton fluxes on 29 and 30 October were significantly more than for the solar X-rays at these times. It is seen that, in all cases, intensive proton fluxes with a hard energetic spectrum, penetrate deeply into the atmosphere and produce ionisation which is very strong compared to quiet conditions. This allows both the EISCAT $224 \mathrm{MHz}$ radar and the partial reflection facility to make measurements of electron density even in the lower D-region, at altitudes $h<60-65 \mathrm{~km}$. 

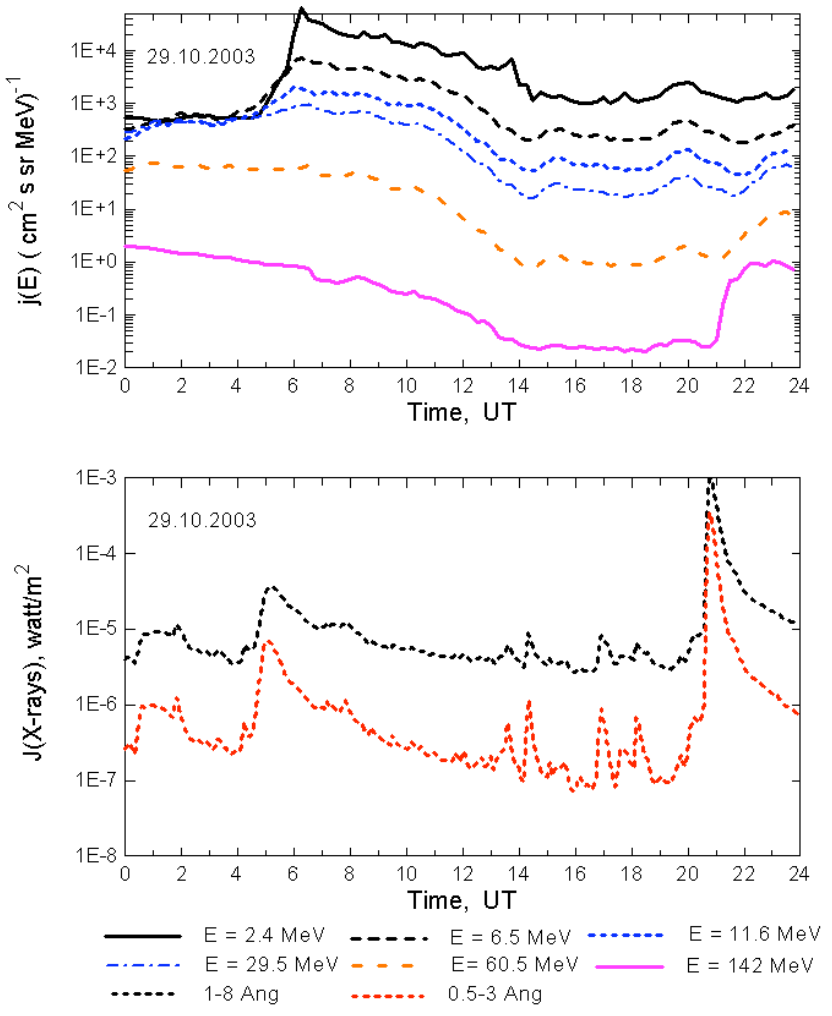

Fig. 3 . Differential solar proton fluxes and hard solar X-rays intensity observed on 29 October 2003.

2.3 Electron density, parameters $f^{+}$and $\lambda$, and effective recombination coefficient in the sunlit ionosphere

Figure 5 presents profiles of electron density measured by the incoherent scatter (red lines) and partial reflection (colour symbols) methods at 09:50 UT (upper panel) and 12:45 UT (lower panel) on 17 January 2005. First of all it should be noted that the electron density has been measured by the partial reflection method (PRM) at $2.4 \mathrm{MHz}$ only inside a narrow height range, $55-65 \mathrm{~km}$. The solar zenith angles, $\chi$, for the two radars differ by $1^{\circ}$ at 09:50 UT and by $3^{\circ}$ at 12:45 UT. When there is little difference in the $\chi$, i.e. $1^{\circ}$ (09:50 UT), both methods give the same values of electron density at $h=60-65 \mathrm{~km}$. For a difference in $\chi$ of $3^{\circ}$, the electron densities obtained with the two radars differ. In Fig. 6, $N_{e}$-profiles measured with the EISCAT radar (red lines) are presented for 10:00 UT on 29 October $2003\left(\chi=84.7^{\circ}\right)$ and 09:00 UT on 30 October $2003\left(\chi=86.7^{\circ}\right)$. The experimental $N_{e}$-profiles are compared with model profiles. The red dotted lines show values of electron density calculated assuming that the concentration of the minor neutral species does not change during the SPE (i.e. using $\mathrm{O}, \mathrm{O}_{3}$ and NO-profiles 1-3 in Fig. 1). In this case, at $\chi \leq 90^{\circ}$, the model $N_{e}$ values exceed the experimental values in the lower part of the D-region by

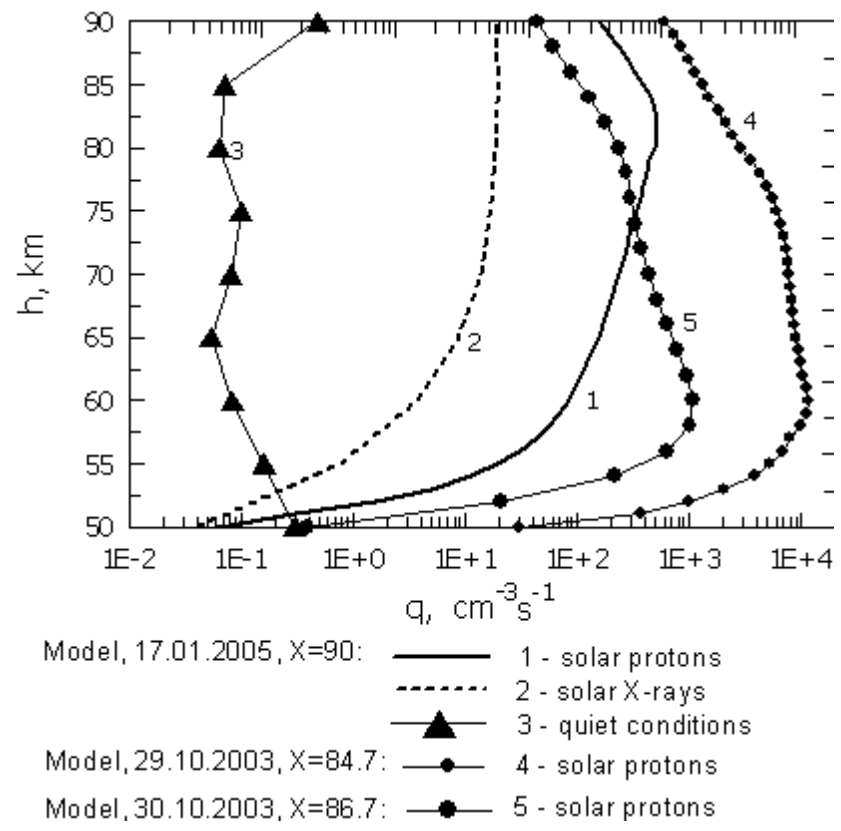

Fig. 4. Ion pair production rate profiles produced in the lower ionosphere with solar proton fluxes in the energy range $2.4-100 \mathrm{MeV}$ (curve 1), solar X-rays (curve 2) and in quiet conditions (curve) calculated for 09:50 UT on 17 January 2005. Curve 4 and 5 - ion pair production rate profiles produced with solar proton fluxes at 10:00 UT on 29 October 2003 and 09:00 UT on 30 October 2003.

a noticeable amount. As $\chi$ increases, the influence of minor neutral constituent concentration decreases. The black lines show $N_{e}$-profiles calculated taking account of the changed $\mathrm{O}, \mathrm{O}_{3}$, NO concentrations during SPE (the $\mathrm{O}, \mathrm{O}_{3}$ and NOprofiles $4-6$ in Fig. 1). It is seen that they are close to the measured $N_{e}$ values at all $\chi$. Note that the model results correctly describe the changes of electron density caused by changes of $\chi$. In particular, since we can assume the same ionisation rate at the two sites at any time when solar proton precipitation dominates (see e.g. Verronen et al., 2007), the differing $\chi$ between the sites provide a very sensitive test of the $\chi$ dependence of the ionospheric response. For the same ion production rate at 12:45 UT the model computations reproduce well the difference in the electron density at $h \leq 70 \mathrm{~km}$ between EISCAT and PRM (Fig. 5b) due to the $\chi$ difference of $3^{\circ}$.

Figures 7 and 8 show the height distribution of the parameters $f^{+}$(upper panel) and $\lambda$ (middle panel) and effective recombination coefficient (lower panel) calculated at 09:50 UT on 17 January 2005 and at 10:00 UT on 29 October 2003 for quiet conditions (blue lines) and during proton precipitation (dashed red lines for the $\mathrm{O}_{2} \mathrm{O}_{3}$ and NO-profiles 1 3; black lines for the $\mathrm{O}, \mathrm{O}_{3}$ and NO-profiles 4-6 in Fig. 1). Changes in the $f^{+}$-values due to the growth of the ion production rate alone (dashed red line) are very large compared to quiet conditions, by factors of 5 and 10, on 17 January and 


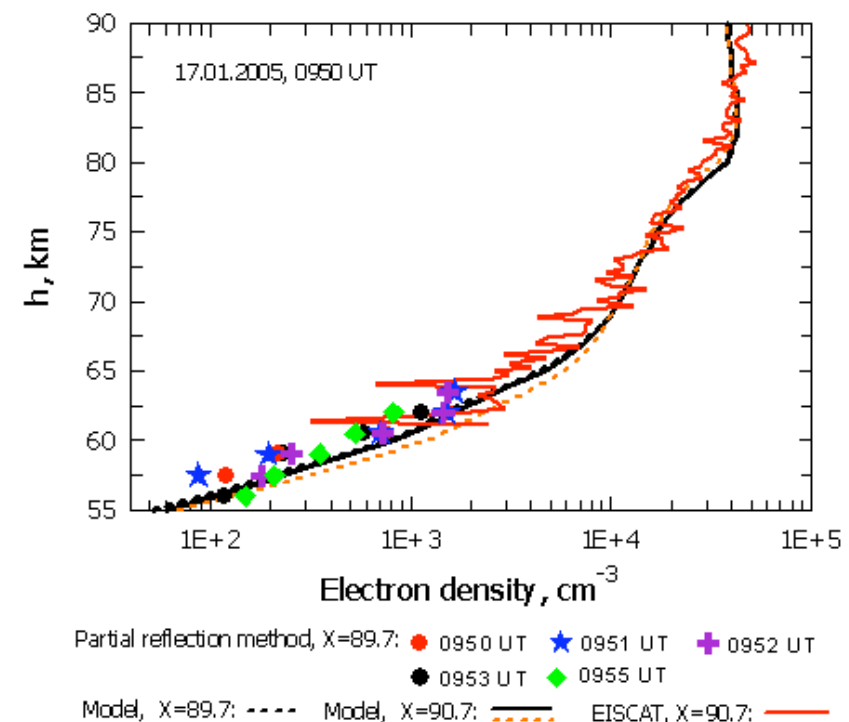

Fig. 5a. Electron density profiles measured (red solid curve and symbols) and calculated for the SPE on 17 January 2005 at 09:50 UT for zenith angles $89.7^{\circ}$ and $90.7^{\circ}$ using the $\mathrm{O}, \mathrm{O}_{3}$ and NO profiles $4-6$ in Fig. 1 (black curve) and using the $\mathrm{O}, \mathrm{O}_{3}$ and NO-profiles 1-3 in Fig. 1 (red dashed curve).

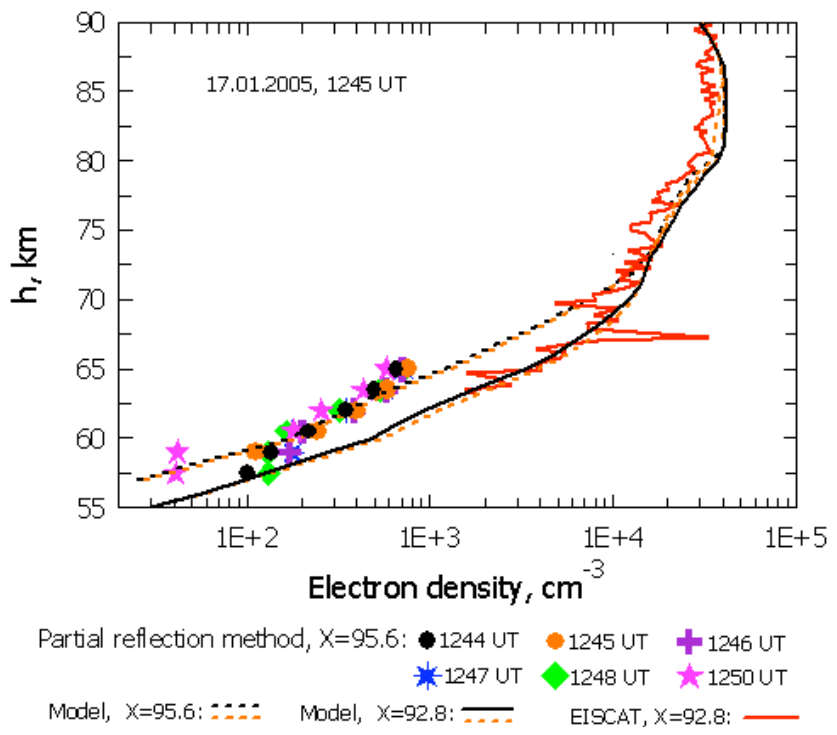

Fig. 5b. Electron density profiles measured (red curve and symbols) and calculated for the SPE on 17 January 2005 at 12:45 UT for zenith angles $92.8^{\circ}$ and $95.6^{\circ}$ using the $\mathrm{O}, \mathrm{O}_{3}$ and NO profiles 4-6 in Fig. 1 (black curve) and using the $\mathrm{O}, \mathrm{O}_{3}$ and $\mathrm{NO}$ profiles $1-3$ in Fig. 1 (red dashed curve).

29 October, respectively. The transition height $h_{f^{+}=1}$ describing the equilibrium between positive clusters and simple molecular ions is lowered by several $\mathrm{km}$. The parameter $\lambda$ does not change with enhancement of the ion production

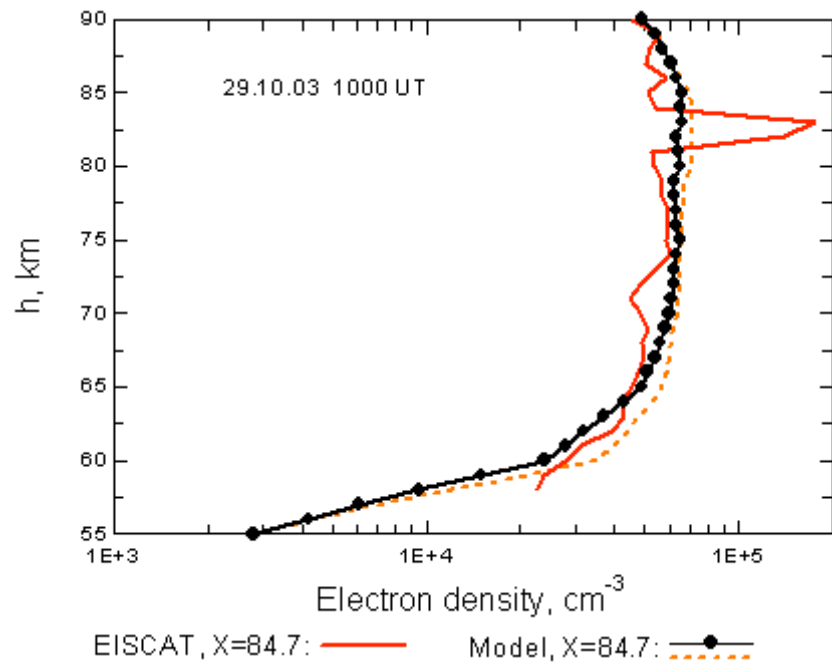

Fig. 6a. Electron density profiles measured by EISCAT radar (red curve) and calculated for the SPE on 29 October 2003 at 10:00 UT for zenith angle $84.7^{\circ}$ and $90.7^{\circ}$ (black curve)using the $\mathrm{O}, \mathrm{O}_{3}$ and NO profiles $4-6$ in Fig. 1. Red dashed curve using the $\mathrm{O}, \mathrm{O}_{3}$ and NO profiles $1-3$ in Fig. 1.

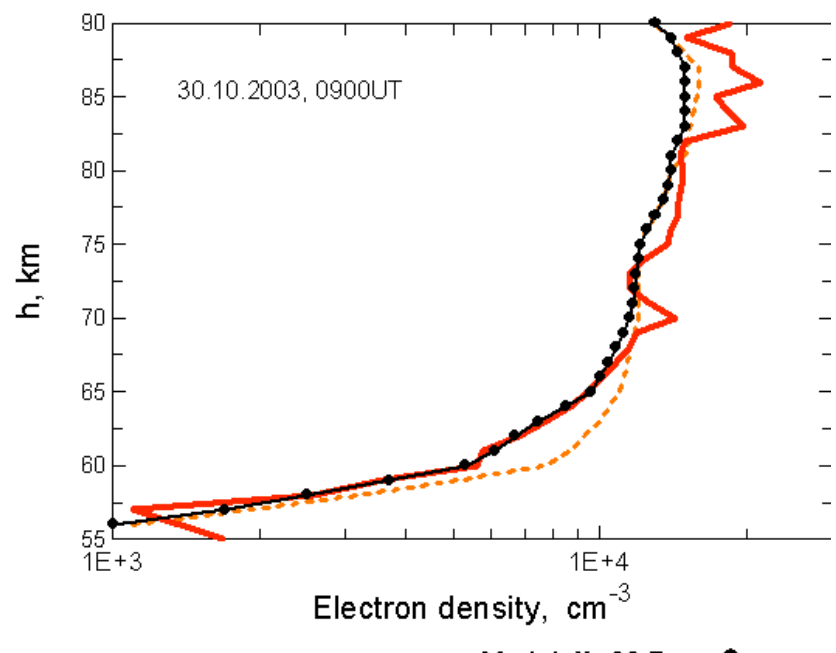

Fig. 6b. electron density profiles measured by EISCAT radar (red curve) and calculated for the SPE on 30 October 2003 at 09:00 UT for zenith angle $86.7^{\circ}$ (black curve) using the $\mathrm{O}, \mathrm{O}_{3}$ and $\mathrm{NO}$ profiles $4-6$ in Fig. 1. Red dashed curve using the $\mathrm{O}, \mathrm{O}_{3}$ and $\mathrm{NO}$ profiles $1-3$ in Fig. 1.

rate alone. As a result the effective recombination coefficient decreases very strongly at altitudes $h>60 \mathrm{~km}$. Changes of the minor neutral species concentration during SPE partly compensate for the effect on the $f^{+}$- parameter of the sharp increase of the ion production rate. Changes of the minor neutral species also lead to large changes (by factors 2-5) of 


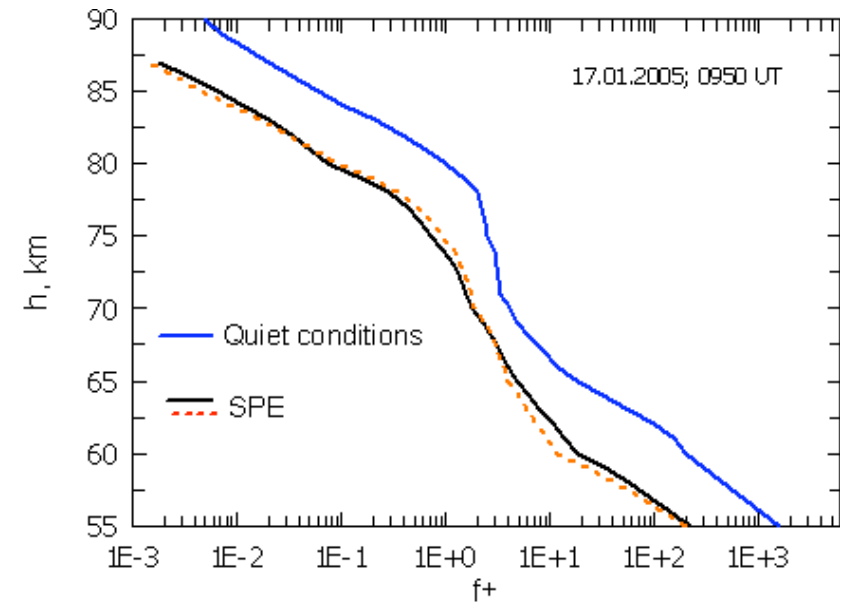

Fig. 7a. $f^{+}$profiles calculated for quiet conditions (blue curve) using the $\mathrm{O}, \mathrm{O}_{3}$ and $\mathrm{NO}$ profiles $1-3$ in Fig. 1 and for the SPE on 17 January 2005 at 09:50 UT using profiles 4-6 in Fig. 1 (black curve) and 1-3 in Fig. 1 (red dashed curve).

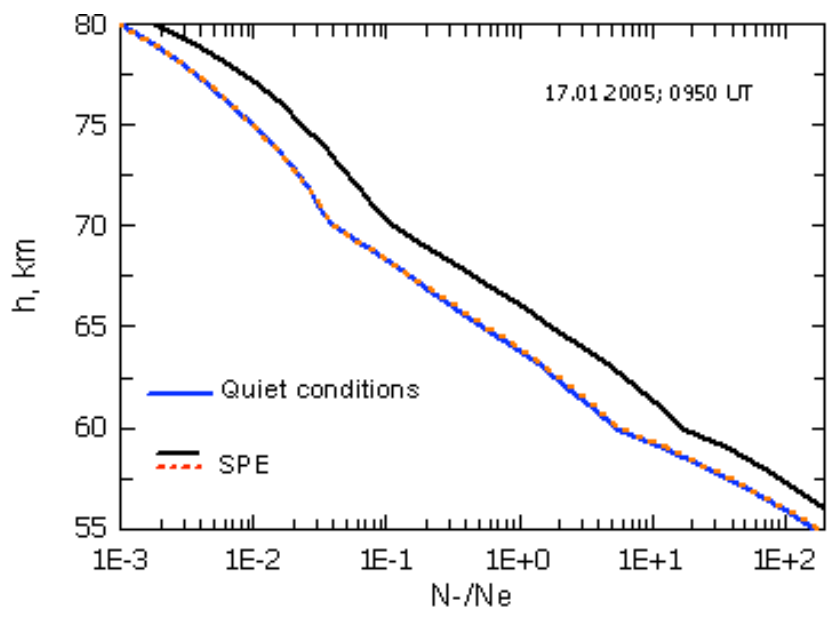

Fig. 7b. $\lambda$ profiles calculated for quiet conditions (blue curve) using the $\mathrm{O}, \mathrm{O}_{3}$ and $\mathrm{NO}$ profiles $1-3$ in Fig. 1 and for the SPE on 17 January 2005 at 09:50 UT using profiles 4-6 in Fig. 1 (black curve) and $1-3$ in Fig. 1 (red dashed curve).

the $\lambda$ parameter. The position of the transition height $h_{\lambda=1}$, describing the height where the total density of negative ions equals the electron density, moves to a higher altitude. The effective recombination coefficient in the lower D-region (at $h<70 \mathrm{~km}$ ) during SPE is significantly increased (by factors 2-3), when we take account of the change of the minor neutral species concentrations caused by proton precipitation.

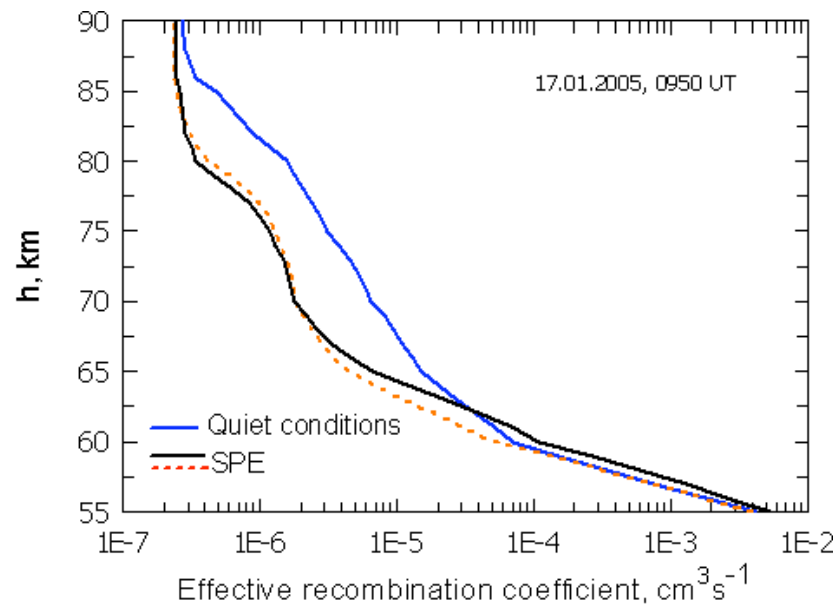

Fig. 7c. $\alpha_{\text {eff }}$ profiles calculated for quiet conditions (blue curve) using the $\mathrm{O}, \mathrm{O}_{3}$ and $\mathrm{NO}$ profiles $1-3$ in Fig. 1 and for the SPE on 17 January 2005 at 09:50 UT using profiles 4-6 in Fig. 1 (black curve) and 1-3 in Fig. 1 (red dashed curve).

\subsection{Electron density and effective recombination coeffi- cient profiles at different solar zenith angles}

In Figs. 5 and 9-11 we show electron density profiles obtained with the EISCAT radar and the partial reflection method during the SPE on 17 January 2005 at the same universal times (UT), but different local times (LT). At times when intensive solar proton fluxes are precipitating, the partial reflection facility is able to determine electron densities only within the height interval, between 55 and $70 \mathrm{~km}$. During SPE, the EISCAT radar is able to measure electron densities starting from $60-62 \mathrm{~km}$. Thus there is narrow range, from about 60 to about $65-67 \mathrm{~km}$, where we can compare measurements of $N_{e}$ values between the two. At times close to local noon, when the $\chi$ at the two sites at the same UT differ only a little $\left(1-2^{\circ}\right)$, both experimental methods give the same or close to the same $N_{e}$ values. During the twilight period, at the same moment of UT, the difference between $\chi$ for the two facilities increases. $N_{e}$ values begin to differ significantly between the two locations, especially during sunset periods when the EISCAT radar measures electron density at $\chi$ which are still less than $96^{\circ}$ but the partial reflection radar measures electron density in the night ionosphere $\left(\chi \geq 99^{\circ}\right)$. When both radars are in night conditions, $N_{e}$ values at the joint altitudes again converge. Since the measurements at the two radars are independent, this is first of all a good indication that the experimental electron densities are correct. Note that, during quiet conditions, or during normal auroral disturbances, it is not possible to make accurate measurements of electron density at such low altitudes because the electron densities are too low.

The model allows us to calculate electron density profiles starting at $55 \mathrm{~km}$ altitude. It can be seen that the model $N_{e}$ 


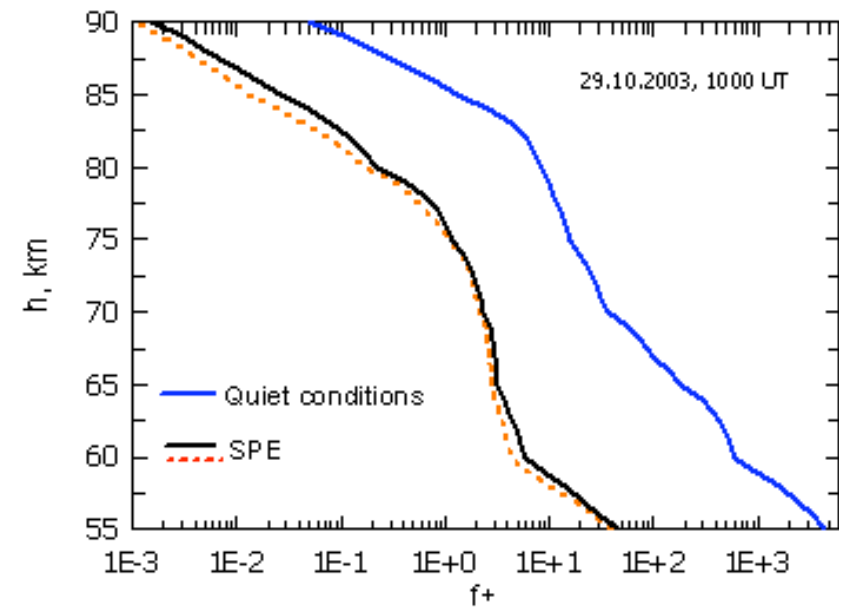

Fig. 8a. $f^{+}$profiles calculated for quiet conditions (blue curve) using the $\mathrm{O}, \mathrm{O}_{3}$ and NO profiles $1-3$ in Fig. 1 and for the SPE on 29 October 2003 at 10:00 UT using profiles 4-6 in Fig. 1 (black curve) and 1-3 in Fig. 1 (red dashed curve).

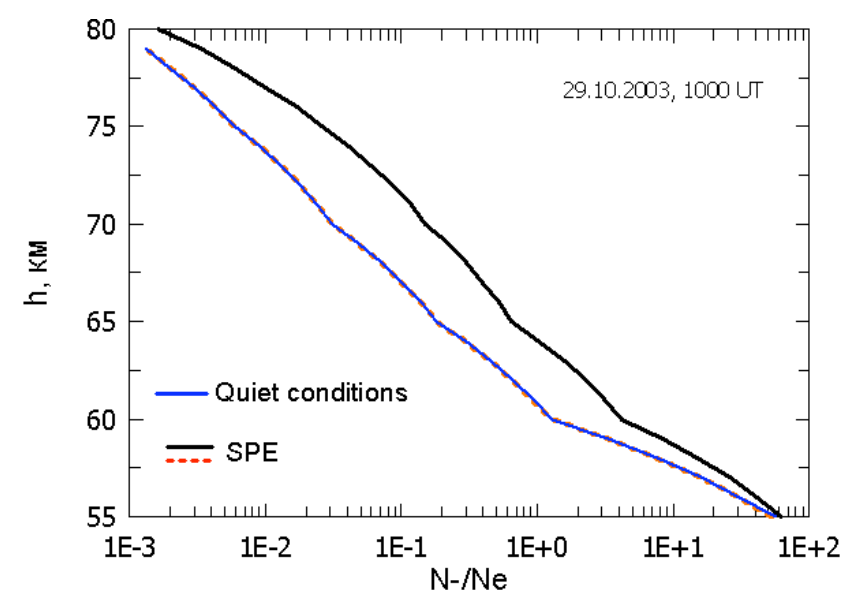

Fig. 8b. $\lambda$ profiles calculated for quiet conditions (blue curve) using the $\mathrm{O}, \mathrm{O}_{3}$ and NO profiles $1-3$ in Fig. 1 and for the SPE on 29 October 2003 at 10:00 UT using profiles 4-6 in Fig. 1 (black curve) and $1-3$ in Fig. 1 (red dashed curve).

profiles calculated for the SPE-conditions (for ion production rates produced by solar protons and the $\mathrm{O}, \mathrm{O}_{3}$ and NOprofiles 4-6 in Fig. 1) reproduce well the experimental data obtained with both radars and describe correctly the changes of the $N_{e}$ values associated with changes of $\chi$. This implies that the model describes accurately the changes of the minor neutral species concentrations due to changes of $\chi$. Based on the results of the comparison between the two sets of experimental data and between the measured and model $N_{e}$ profiles, we present in Fig. 12 the effective recombination coefficient profiles calculated for the D-region at the different $\chi$ during the SPE on 17 January 2005.

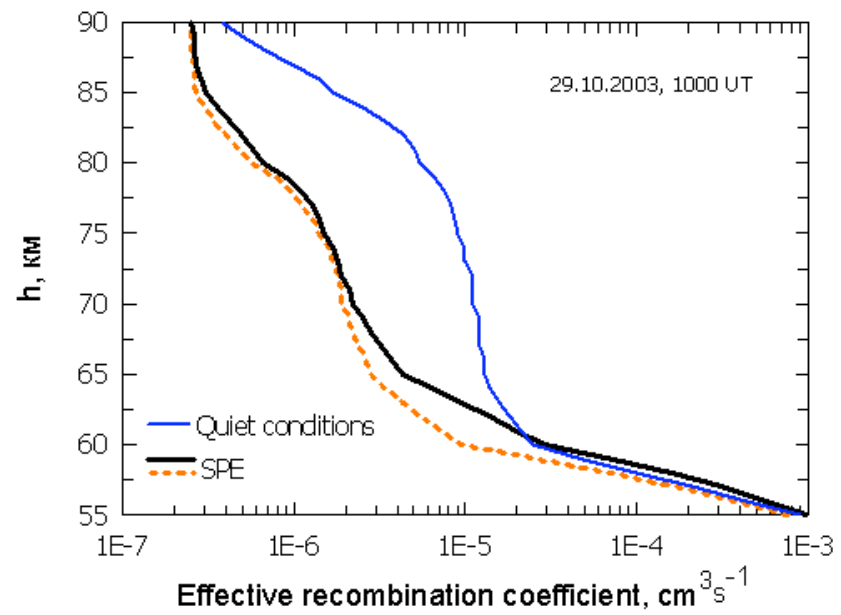

Fig. 8c. $\alpha_{\text {eff }}$ profiles calculated for quiet conditions (blue curve) using the $\mathrm{O}, \mathrm{O}_{3}$ and NO profiles $1-3$ in Fig. 1 and for the SPE on 29 October 2003 at 10:00 UT using-profiles 4-6 in Fig. 1 (black curve) and 1-3 in Fig. 1 (red dashed curve).

\section{Conclusions}

Accurate measurements of the free electron concentration in the lower D-region (at $h<70 \mathrm{~km}$ ) using ground-based facilities or sounding rockets are as a rule not available during quiet conditions or during auroral electron precipitation. Deep penetration into the atmosphere of high-energy solar proton fluxes (SPE) produces an extra ionisation in the whole D-region including the lower altitudes. During the SPE on 17 January 2005, electron densities have been measured with two different ground-based techniques, namely incoherent scatter of radio waves using the EISCAT $224 \mathrm{MHz}$ radar in Troms $\varnothing$, Norway $\left(69.6^{\circ} \mathrm{N}, 19.3^{\circ} \mathrm{E}\right)$, and the partial reflection of radio-waves using the $2.8 \mathrm{MHz}$ radar in Murmansk, Russia $\left(69.0^{\circ} \mathrm{N}, 35.7^{\circ} \mathrm{E}\right)$. Information on electron density has been obtained for heights between $57 \mathrm{~km}$ and $90 \mathrm{~km}$ with the EISCAT radar and in the range $55-70 \mathrm{~km}$ with the partial reflection technique. At the same moments of universal time, solar zenith angles, at the places where that facilities are located, differ by about $1-2^{\circ}$ at hours close to noon and by about $3-5^{\circ}$ during the twilight period. Comparison of the experimental data obtained with the two radars near noon shows that, for little difference in the zenith angle $\left(1-2^{\circ}\right)$, both methods give close to the same values of electron density at the joint altitudes $(h=60-65 \mathrm{~km})$. Maximum differences between electron densities at the two radars are observed during the twilight period. Measurements with both radars in the night ionosphere $\left(\chi \geq 99^{\circ}\right)$ again give close to the same $N_{e}$ values. Thus we find that the experimental data are sufficiently accurate for us to use them for verification of the model computations.

We use a theoretical model of the D-region, including ion chemistry and ionisation calculations, to compute electron 


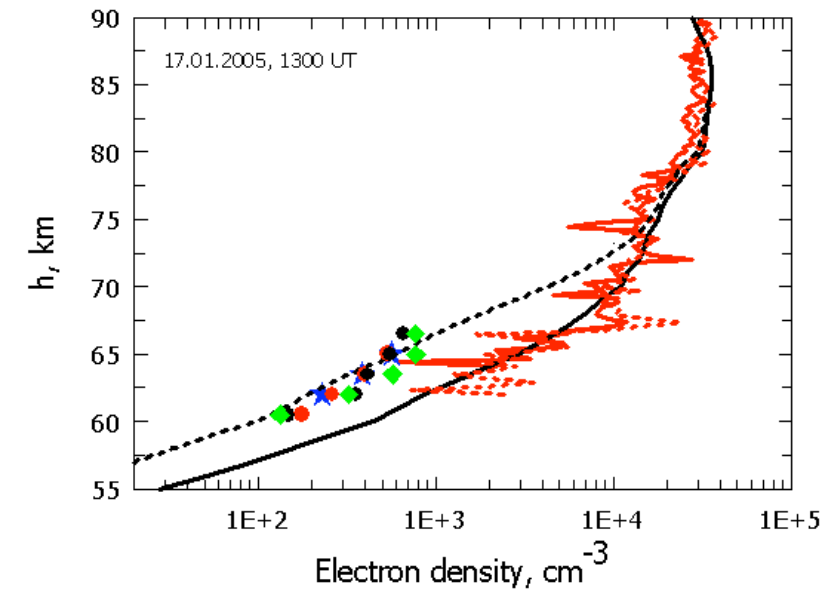

Partial reflection method, $x=96.2:-1258$ UT 1300 UT $>1301$ UT $\nless 1304$ UT Model, $X=96.2: \cdots \quad$ Model, $X=93.4:-\quad$ EISCAT, $X=93.4:-$

Fig. 9a. Electron density profiles measured (red solid curve and symbols) and calculated for the SPE on 17 January 2005 at 13:00 UT for zenith angles $93.4^{\circ}$ and $96.2^{\circ}$ using the $\mathrm{O}, \mathrm{O}_{3}$ and NO profiles 4-6 in Fig. 1 (black curve).

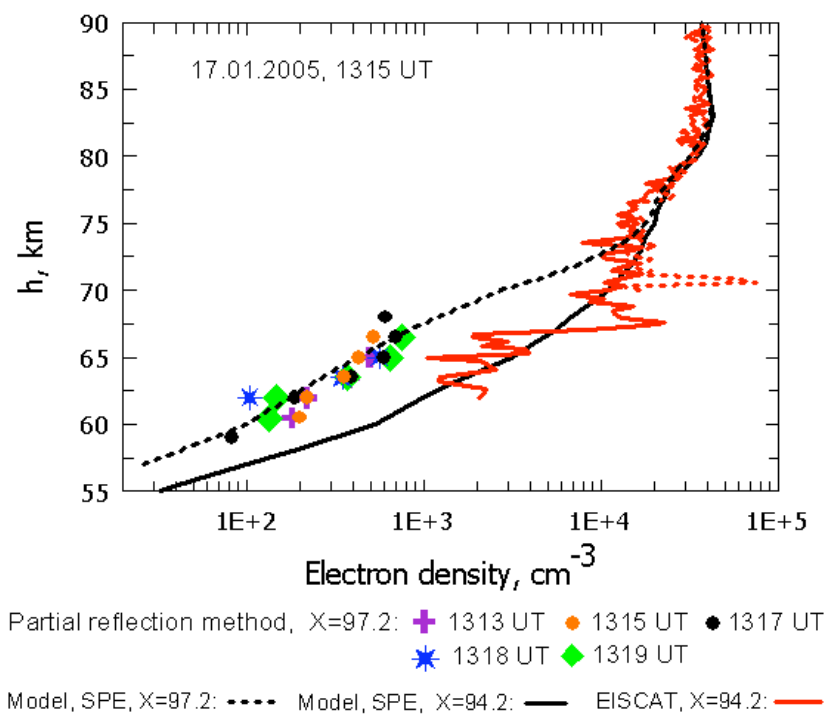

Fig. 9b. Electron density profiles measured (red curve and symbols) and calculated for the SPE on 17 January 2005 at 13:15 UT for zenith angles $94.2^{\circ}$ and $97.2^{\circ}$ using the $\mathrm{O}, \mathrm{O}_{3}$ and NO profiles 4-6 in Fig. 1 (black curve).

density and effective recombination coefficient profiles at different $\chi$ during SPE. Using numerical modelling we have separated effects due directly to the growth of the ion production rate and those due to changes in concentration of the minor neutral species $\left(\mathrm{NO}, \mathrm{O}, \mathrm{O}_{3}\right)$ during solar proton precipitation and have estimated their contribution to changes of ionospheric parameters $\left(N_{e}, f^{+}, \lambda, \alpha_{\mathrm{eff}}\right)$.

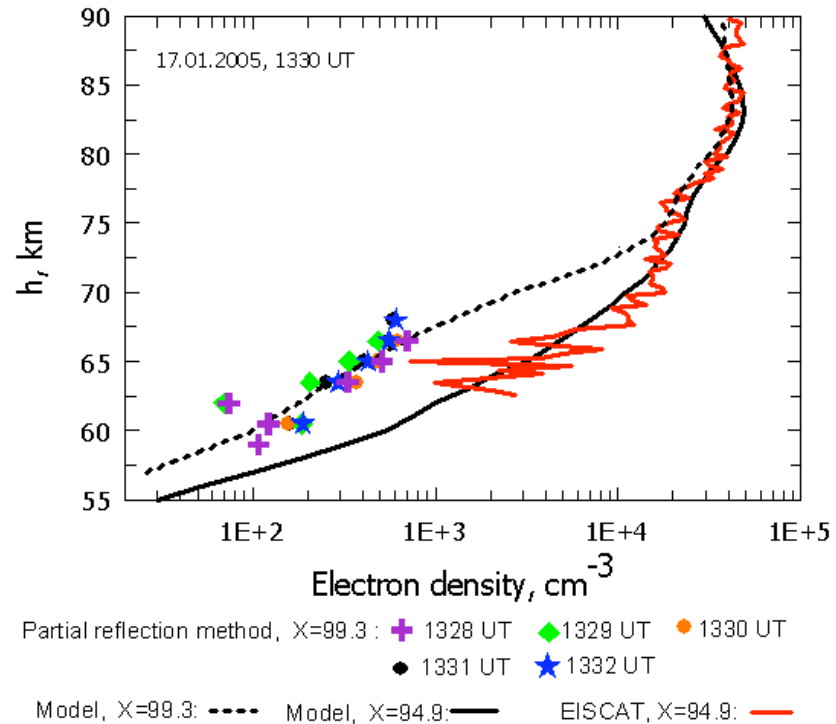

Fig. 10a. Electron density profiles measured (red solid curve and symbols) and calculated for the SPE on 17 January 2005 at 13:30 UT for zenith angles $94.9^{\circ}$ and $99.3^{\circ}$ using the $\mathrm{O}, \mathrm{O}_{3}$ and NO profiles 4-6 in Fig. 1 (black curve).

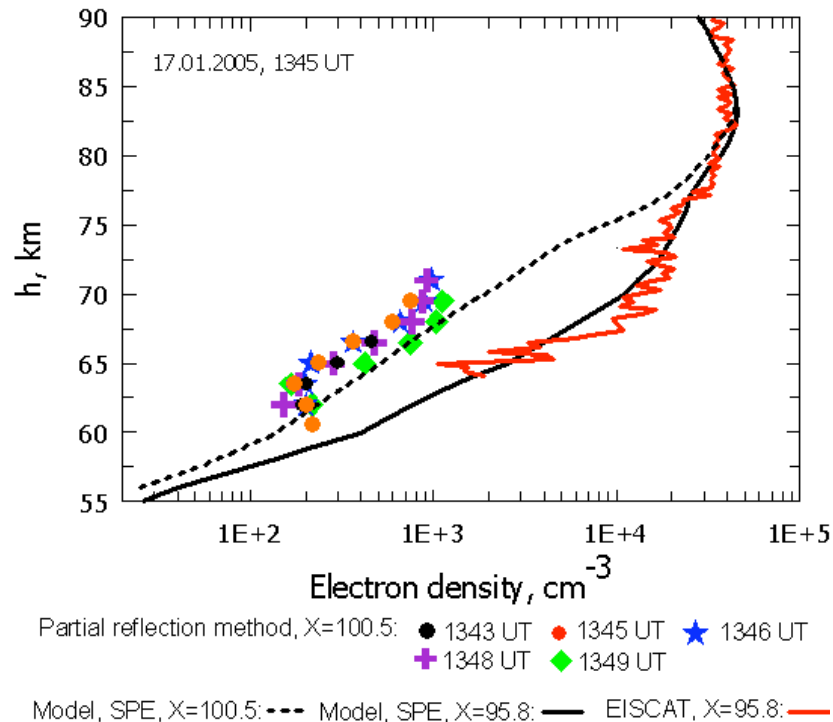

Fig. 10b. Electron density profiles measured (red curve and symbols) and calculated for the SPE on 17 January 2005 at 13:45 UT for zenith angles $95.8^{\circ}$ and $100.5^{\circ}$ using the $\mathrm{O}, \mathrm{O}_{3}$ and NO profiles 4-6 in Fig. 1 (black curve).

Growth of the ion production rate by $2-3$ orders of magnitude compared to quiet conditions leads to a significant decrease in the $f^{+}$-values and a change in the transition height $h_{f^{+}=1}$ by several $\mathrm{km}$, as a result of redistribution of the relative abundances of positive cluster ions and simple molecular 


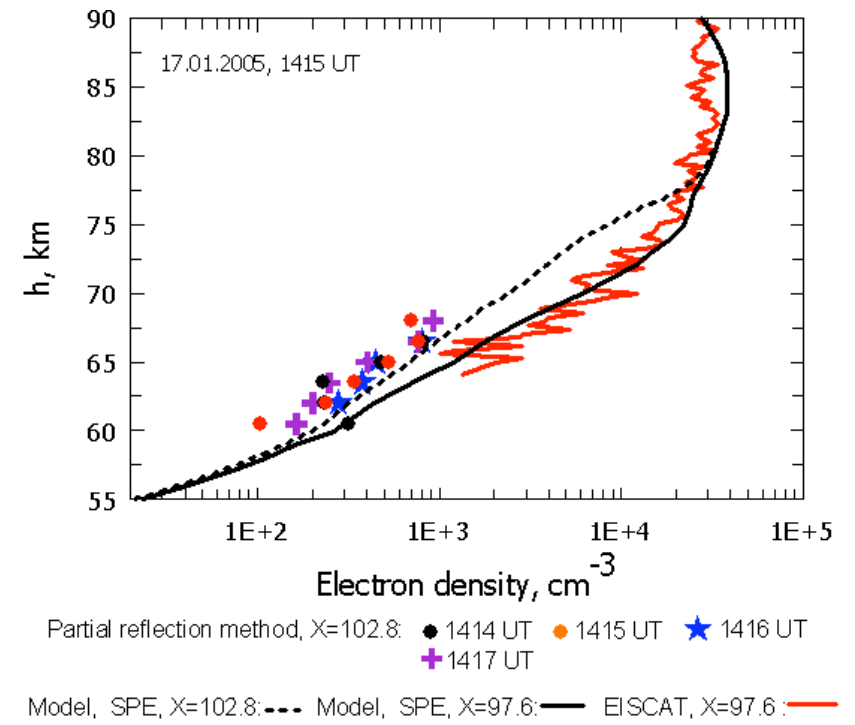

Fig. 11a. Electron density profiles measured (red solid curve and symbols) and calculated for the SPE on 17 January 2005 at 14:15 UT for zenith angles $97.6^{\circ}$ and $102.8^{\circ}$ using the $\mathrm{O}, \mathrm{O}_{3}$ and NO profiles 4-6 in Fig. 1 (black curve).

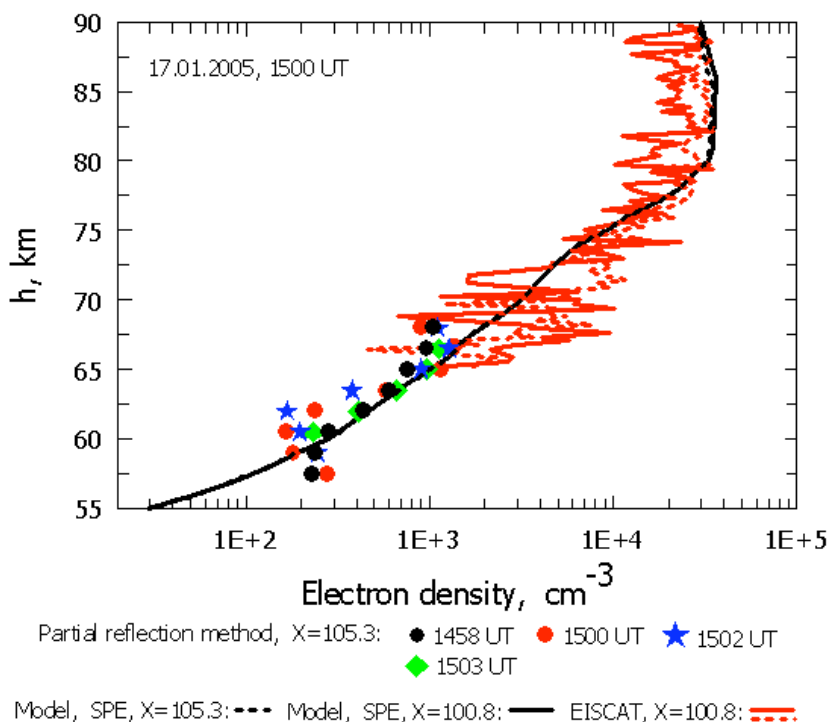

Fig. 11b. Electron density profiles measured (red curve and symbols) and calculated for the SPE on 17 January 2005 at 15:00 UT for zenith angles $100.8^{\circ}$ and $105.3^{\circ}$ using the $\mathrm{O}, \mathrm{O}_{3}$ and NO profiles $4-6$ in Fig. 1 (black curve).

ions. This leads to a significant decrease in the effective recombination coefficient throughout the D-region (red dashed lines in Figs. 7, 8). Considering this effect alone, our model computations show $N_{e}$ values for $\chi \approx 90^{\circ}$ and less than $90^{\circ}$ which are higher (by about a factor 1.5-2) than the measured $N_{e}$ at altitudes below $70 \mathrm{~km}$ (Figs. 5, 6). However, when we

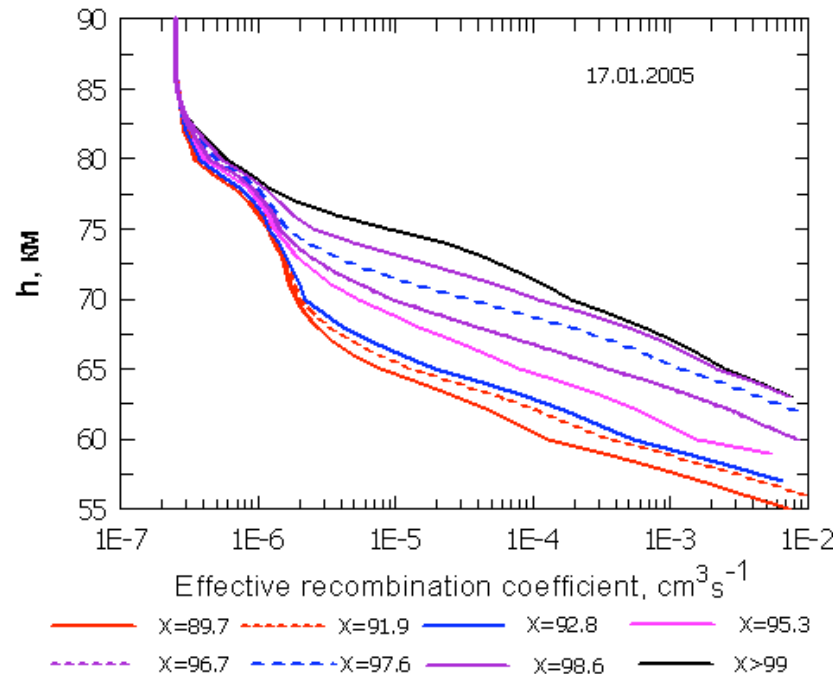

Fig. 12 . Effective recombination coefficient profiles calculated for the D-region at different solar zenith angles during the SPE on 17 January 2005.

take into account changes of atomic oxygen, ozone and nitric oxide concentrations (the $\mathrm{O}, \mathrm{O}_{3}$ and NO-profiles 4-6 in Fig. 1) caused by long duration precipitation of solar protons, the model $N_{e}$ profiles reproduce, or are close to, the experimental $N_{e}$ values. Numerical modelling shows that, in the sunlit ionosphere, the effect of changes in minor neutral species concentration is primarily displayed in the lower Dregion (between $55-70 \mathrm{~km}$ ) (Figs. 5-8). The main cause is changes in odd oxygen (Osepian et al., 2008, 2009). For the same ion production rate, the total concentration of negative ions and the $\lambda$ values increase and the transition height $h_{\lambda=1}$ rises by several $\mathrm{km}$. The effect of the changed concentrations of the minor neutral species on the $f^{+}$-parameter mainly consists in a slight increase of proton-hydrated cluster ions and of the $f^{+}$-values in the lower part of the D-region due to a decrease of $[\mathrm{O}]$ and $\left[\mathrm{O}_{3}\right]$. A slight increase of $f^{+}$in the upper part of the D-region is caused by a decrease of $\left[\mathrm{O}_{2}^{+}\right]$. Thus the strong decrease of the $\alpha_{\text {eff-values associ- }}$ ated with growth of the ion production rate is partly compensated if we take in account a decrease of odd oxygen during SPE. The efficiencies of the reactions with atomic oxygen and ozone are changed which leads to redistribution of the relative abundances of ions, both positive and negative ions (Osepian et al., 2008, 2009). In the dark ionosphere, the influence of minor species concentration on the ionisation balance is less and the influence of changes in the atomic oxygen, ozone and nitric oxide concentrations on the ionospheric parameters becomes negligible.

We have shown that model $N_{e}$ profiles, calculated for the same ion production rate but different $\chi$, reproduce the differences in the experimental $N_{e}$ values obtained with the two radars at different $\chi$ (Figs. 9-11). This shows that the 
dependence of the odd oxygen concentration on $\chi$ in the model is correct. It means that the model describes correctly the height distributions of effective recombination coefficient at the different $\chi$ during the SPE on 17 January 2005 (Fig. 12). It is clear that in the sunlit ionosphere $\left(\chi<90^{\circ}\right)$, in the height range $68-77 \mathrm{~km}, \alpha_{\text {eff }}$ is determined by the dissociative recombination coefficient of the hydrated ion cluster family, with $\alpha \approx 10^{-6} \mathrm{~cm}^{3} \mathrm{~s}^{-1}$. At altitudes above $80 \mathrm{~km}, \alpha_{\text {eff }}$ is determined by the dissociative recombination coefficients of $\mathrm{O}_{2}^{+}$and $\mathrm{NO}^{+}$ions. At altitudes below $67 \mathrm{~km}$ it is determined by the coefficient of ion-ion recombination between positive and negative ions and by the dissociative recombination coefficient of the proton hydrate Cluster ${ }_{2}^{+}$family. Changes in the shape of the $\alpha_{\text {eff }}$ profile and in the absolute values of $\alpha_{\text {eff }}$ with increasing $\chi$ are due to changes of efficiency of ion-molecular reactions with minor neutral species and ion-ion reactions.

Acknowledgements. This research is partly supported by the RFFI grant No. 07-05-00012 and by the Swedish Academy of Sciences (KVA). EISCAT is an international association supported by the research councils of Norway, Sweden, Finland, Japan, China, the United Kingdom and Germany.

Topical Editor M. Pinnock thanks M. Friedrich and another anonymous referee for their help in evaluating this paper.

\section{References}

Arnold, F.: The middle atmosphere ionized component, Proc. 5th ESA Symposium on Rocket and Balloon Programmes, Boumemouth, SP-152, 479-496, 1980.

Arnold, F. and Krankowsky, D.: Negative ions in the lower ionosphere. A comparison of a model computation and a massspectrometric measurement, J. Atmos. Terr. Phys., 33, 16931702, 1971.

Bilitza, D. and Reinisch, B.: International Reference Ionosphere 2007: Improvements and new parameters, J. Adv. Space Res., 42, 599-609, doi:10.1016/j.asr.2007.07.048, 2008.

Chakrabarty, D., Chakrabarty, P., and Witt, G.: An attempt to identify the obscured paths of water positive ions build-up in the Dregion, J. Atmos. Terr. Phys., 40, 437-442, 1978.

Danilov, A. D.: Photochemistry of the D-region, Ionosfernye Issledovaniya, 34, 6-38, 1981.

Danilov, A. D. and Smirnova, N. V.: Ion composition and photochemistry of the lower thermosphere. 2. Ion composition of the D- and E-regions, Geomagn. Aeron., 33, 120-133, 1993.

Ferguson, E. E.: D-region ion chemistry, Rev. Geophys. Space Phys., 9, 997-1008, 1976.

Friedrich, M. and Kirkwood, S.: The D-region background at high latitudes, Adv. Space. Sci., 25, 15-23, 2000.

Friedrich, M. and Torkar, K.: An empirical model of the nonauroral D-region, Radio Sci., 27, 945-953, 1992.

Friedrich, M. and Torkar, K.: Typical behavior of the high latitude lower ionosphere, Adv. Space Res., 16, 73-81, 1995.

Friedrich, M. and Torkar, K.: Empirical D-region modeling, a progress report., Adv. Space Res., 22, 757, 1998a.
Friedrich, M. and Torkar, K.: Comparison between an empirical and a theoretical model of the D-region, Adv. Space Res., 21, 895-904, 1998b.

Friedrich, M. and Torkar, K.: FIRI: A semiempirical model of the lower ionosphere., J. Geophys. Res., 106, 21409-21418, 2001.

Friedrich, M., Egger, G., McKinnel, L., and Belova, E.: Perturbations in EISCAT electron density visualized by normalization, Adv. Space Res., 38, 2413-2417, 2006.

Jackman, C. H. and McPeters, R. D.: The effect of solar proton events on ozone and other constituents, in: Geophysical Monograph 141, pp. 305-319, American Geophysical Union, 2004.

Kazil, J., Kopp, E., Chabrillat, S., and Bishop, J.: The University of Bern Atmospheric Ion Model: Time dependent modeling of the ions in the mesosphere and lower thermosphere, J. Geophys. Res., 18, 4432, doi:10.1029/2002JD003024, 2003.

Kirkwood, S. and Osepian, A.: Quantitative studies of energetic particle precipitation using incoherent scatter radar, J. Geomag. Geoelectr., 47, 783-799, 1995.

Kirkwood, S., Osepian, A., and Smirnova, N.: Quantitative description of electron precipitation during auroral absorption events in the morning and around noon local time sectors, J. Atmos. SolarTerr. Phys., 63, 1907-1921, 2001.

Kull, A., Kopp, E., Granier, C., and Brasseur, G.: Ions and electrons of the lower-latitude D-region., J. Geophys. Res., 102, 97059716, 1997.

McKinnell, L. A. and Friedrich, M.: A neural network-based ionospheric model for the auroral zone., J. Atmos. Solar Terr. Phys., 69, 1459-1470, 2007.

NGDC: http://goes.ngdc.noaa.gov/data/avg/2005, Tech. rep., National Geophysical Data Center,Boulder, USA, access: 1 April 2008.

Ogawa, T. and Shimazaki, T.: Diurnal variations of odd nitrogen and ionic densities in the mesosphere and lower thermosphere: simultaneous solution of photochemical-diffusive equations, J. Geophys. Res., 80, 3945-3960, 1975.

Osepian, A. and Kirkwood, S.: High-energy electron fluxes derived from EISCAT electron density profiles, J. Atmos. Terr. Phys., 58, 479-487, 1996.

Osepian, A. and Smirnova, N.: Modelling of absorption layer during auroral absorption events, J. Atmos. Solar Terr. Phys., 59, 951-960, 1997.

Osepian, A., Kirkwood, S., and Smirnova, N.: Effective recombination coefficients in the D and E- regions during auroral absorption events, in: Proc.12th ESA Symposium, Lillehammer, vol. ESA-SP 370, pp. 263-268, 1995.

Osepian, A., Smirnova, N., and Kirkwood, S.: Precipitation of energetic electrons into the high-latitude atmosphere in the morning local sectors, Cosmic Res., 38, 33-37, 2000.

Osepian, A., Kirkwood, S., and Smirnova, N.: Variations in the electron density and energy spectrum of precipitating electrons during auroral substoms by the incoherent scatter data, Kosmicheskie Issledovaniya, 39, 332-336, 2001.

Osepian, A., Tereschenko, V., Dalin, P., and Kirkwood, S.: The role of atomic oxygen concentration in the ionization balance of the lower ionosphere during solar proton events, Ann. Geophys., 26, 131-143, 2008, http://www.ann-geophys.net/26/131/2008/.

Osepian, A., Kirkwood, S., and Dalin, P.: The influence of ozone concentration on the lower ionosphere - modelling and measure- 
ments during the 29-30 October 2003 solar proton event, Ann. Geophys., 27, 577-589, 2009, http://www.ann-geophys.net/27/577/2009/.

Reid, G.: The production of water cluster positive ions in the quiet daytime D-region, Planet. Space Sci., 25, 275-290, 1977.

Rodrigo, R., Lopez-Moreno, J., Lopez-Puertas, M., Moreno, F., and A., M.: Neutral atmospheric composition between 60 and 220 $\mathrm{km}$ : A theoretical model for mid-latitudes, Planet. Space Sci., 34, 723-743, 1986.

Shimazaki, T. and Laird, A.: A model calculation of the diurnal variation in minor neutral constituents in the mesosphere and lower thermosphere including transport effects, J. Geophys. Res., 75, 3221-3235, 1970.

Shimazaki, T. and Laird, A.: Seasonal effect on distributions of minor constituents in the mesosphere and lower thermosphere, Radio Sci., 1, 23-43, 1972.

Smirnova, N., Ogloblina, O., and Vlaskov, V.: Modelling of the lower ionosphere, Pageoph, 127, 353-379, 1988.

Swider, W. and Keneshea, T. J.: Decrease of ozone and atomic oxygen in the lower ionosphere during a PCA event, Planet. Space Sci., 21, 1969-1973, 1973.
Swider, W., Keneshea, T. J., and Foley, C. I.: An SPE-disturbed D-region model, Planet. Space Sci., 26, 883-892, 1978.

Turco, R. and Sechrist, C.: An investigation of the ionospheric Dregion at sunrise. 1 . Time variations of ozone, metastable molecular oxygen and atomic oxygen, Radio Sci., 7, 703-716, 1972.

Turunen, E. M. H. and Ranta, H.: Sodankyla ion chemistry (SIC) Model, Report 49, Sodankyla Geophysical Observatory, Finland, 1992.

Verronen, P. T., Turunen, E., Ulich, Th., and Kyrölä, E.: Modelling the effects of the October 1989 solar proton event on mesospheric odd nitrogen using a detailed ion and neutral chemistry model, Ann. Geophys., 20, 1967-1976, 2002, http://www.ann-geophys.net/20/1967/2002/.

Verronen, P. T., Rodger, C. J., Clilverd, M. A., Pickett, H. M., and Turunen, E.: Latitudinal extent of the January 2005 solar proton event in the Northern Hemisphere from satellite observations of hydroxyl, Ann. Geophys., 25, 2203-2215, 2007, http://www.ann-geophys.net/25/2203/2007/.

Zadorozhny, A.: Diffusion-photochemical model of minor neutral constituents in the lower ionosphere, Science Academy of USSR, Novosibirsk, 1982 (in Russian). 